\title{
Exploring the nature of teacher-student interaction in small-group discussions in a Chinese university setting
}

\author{
Mang $\mathrm{Li}^{1}$ • Chunping Zheng ${ }^{1,2}$ Xiaolan Tang ${ }^{1,3}$. \\ Guoyuan Sang
}

Received: 25 June 2015/Revised: 9 August 2015/ Accepted: 11 August 2015/

Published online: 26 August 2015

(C) Beijing Normal University 2015

\begin{abstract}
Rapid evolution of information technology has changed traditional classroom pedagogies, and a number of computer-supported collaborative learning forms have burgeoned. However, research concerning the analysis of teacher-student interaction in actual classroom discussions is still less established. This article addresses the nature of teacher-student interaction in small-group discussions in a Chinese higher education setting. We analysed the social network and verbal behavioural features of teacher-student interaction using an analytical framework that integrates the social network analysis (SNA) and Flanders interaction analysis (FIA). The results of SNA indicated that the teacher exerted the main control of the social network and the group leaders were more actively engaged than other students. The findings of FIA showed a range of teacher-student behavioural characteristics. Teacher lecturing, student-initiated talk and teacher's clarifying student ideas accounted for the largest percentage of interaction. Although the teacher spent a large percentage of talk in lecturing, he acted more like a guide and facilitator, developing student ideas with appropriate comments and providing ample opportunities for student talk. The students as a whole were found to be active in verbal
\end{abstract}

Mang Li

leemangbnu2015@126.com

Chunping Zheng

zhengchunping@bupt.edu.cn

Xiaolan Tang

tx1880911@163.com

Guoyuan Sang

guoyuan.sang@bnu.edu.cn

1 Faculty of Education, Beijing Normal University, Beijing 100875, China

2 School of Humanities, Beijing University of Posts and Telecommunications, Beijing 100876, China

3 Hong Kong University, Hong Kong, China 
behaviours and vigorous in raising questions. This case study provided a framework for analysing teacher-student interactional behaviours in higher education context. It also added our understanding of Chinese professors' and graduate students' experience in small-group discussions.

Keywords Small-group discussions - Teacher-student interaction · Social network features · Verbal behaviours · Higher education

\section{Introduction}

Recent developments in information technologies have created exciting opportunities for their educational use and further boosted the research on promoting active learning with the support of computers (Alavi 1994). An increasing number of studies have investigated the social interactions in computer-supported learning environments (Kreijns et al. 2003; Weinberger and Fischer 2006; Kwon et al. 2014). However, thorough investigations of teacher-student interactional behaviours in an actual classroom still remained to be further explored. Moreover, although there are ample studies addressing the teacher-student interaction and student learning experiences at or below the tertiary level (Murphy et al. 2009; Renn et al. 2014), little is reported about how adult learners at post-graduate level interact with professors in actual classrooms.

In Chinese university classrooms, the professor was expected to be "highly knowledgeable about a subject and to lead and take control of the classroom", while the students were traditionally viewed as "passive recipients of knowledge" (Tam et al. 2009, p. 147-148). However, with the marketization and privatisation in the social-economic context since the late 1980s, especially after China's entry into the WTO since the twenty-first century, China has witnessed a revolutionary transition from elite to mass higher education spurred by a radical expansion policy in 1999 (Li and Lin 2008). This transition called for educational innovations in China's traditional education system. For example, Zheng (2001) suggested restructuring the classroom in China by transforming the traditional classroom as the teachers' stage to a teacher-student interactive stage. Chen (2014) emphasised the importance of understanding what Chinese school teachers actually do in their classrooms before making changes in their teaching approach. Recently, there has been an increasing amount of research concerning the promotion and practice of teacher-student interaction in Chinese classrooms (Gu 2009; Sun 2006). Teachers are encouraged to organise more group work both in and out of classrooms in Chinese educational contexts ( $\mathrm{Li}$ et al. 2014).

This paper reports a case study at one of China's teacher education universities and attempts to delineate the university professor's interaction with graduate students within the formal classroom setting. Particularly, the study focuses on analysing the social network and verbal behavioural features of small-group discussions. It attempts to contribute to a further understanding of Chinese teacherstudent classroom behaviours in Chinese tertiary settings. 


\section{Literature review}

In a higher education context, researchers and practitioners believe that frequent and meaningful teacher-student interaction both inside and outside of the classroom leads to a strong contribution to students' learning and their personal development (Cotten and Wilson 2006). Social support from learners' parents, teachers and peers can positively predict learners' adaptive types of goals (King and Jr. Ganotice 2014). The actual classroom is the primary setting where teacher-student interaction happens, and evidence has shown that learners' interactive activities with a peer or an expert tutor are more beneficial than self-explaining in group learning (Chi 2009; Chi et al. 2008; Osborne 2010). There is a long tradition and also a wide range of research perspectives concerning the nature of teacher-student interaction in actual classrooms. For instance, early in the 1960s, Flanders (1962) proposed an interactional analysis system focusing on the analysis of the teacher-student verbal statement types within classroom communication. Auster and Macrone (1994) analysed the different types of teacherstudent interactive behaviours and found lecturers were most frequent in calling on student volunteers, calling on by students' names and giving students enough time to answer questions. Carroll (2005) proposed an analytic approach from the linguistic perspective, investigated the study group discourse and developed a methodology for understanding the interactive talk. To better understand what was happening in the process of "negotiating meaning", researchers proposed to integrate the traditional data analysis method with the interactive analysis approach. For instance, Martinez et al. (2003) proposed an interpretative approach by integrating the qualitative evaluation with social network analysis (SNA). Cho et al. (2007) applied SNA to understanding teacher-student interaction in the computer-supported collaborative learning (CSCL) community. Kwon et al. (2014) investigated the characteristics of social interactions between good and poor collaborators in a CSCL environment as well and found most groups did not exhibit ideal interactional behaviours as expected. Coll et al. (2014) analysed specific type of teachers' feedback in small groups and revealed the complex role played by the teachers in an online collaborative learning environment. Compared with the heated discussion about the nature of teacher-student interaction with computer and the Internet-based technology, there is still a lack of research on teacher-student interaction situated in the actual classroom discussions.

In-class small-group discussions are considered as a useful teaching strategy offering learners special opportunities for active learning (McKeachie and Hofer 2002), and its merits have been well explained (Lou et al. 1996; Murphy et al. 2009; Nystrand 2006). During discussions, learners incorporate ways of thinking and behaving, foster the knowledge, skills and dispositions, and acquire abilities for independent problem solving (Anderson et al. 2001; Hatano 1993; Murphy et al. 2009). Barnes and Todd (1977) conducted one of the pioneering studies exploring the nature of interaction taking place within small groups. Cohen (1994) reviewed process conditions for successful group learning and suggested a research focus on task and interaction for a better understanding of the effectiveness of small-group learning. Christoph and Nystrand (2001) documented three key strategies that the teacher used to make group discussions possible in the classroom, such as "developing an ethos of 
involvement and respect, using scaffolding and specific ways of phrasing questions to encourage discussion, and, most importantly, acknowledging and making space for the presence of students' interpersonal relationship" (p. 249). McDonough (2004) found that learners demonstrated improved production of the target language forms with more participation during small-group activities, though they did not hold positive perceptions of those activities. These studies are helpful for teachers to understand and further conduct effective classroom discussions. However, we claim that further research should be conducted from the perspective of social interaction, delineating the nature, process, and characteristics of interaction between teachers and students in small-group discussions.

This study attempts to better understand the features of teacher-student interaction within small-group discussions. It is primarily guided by the following two research questions:

1. What are the social network features of the teacher-student interaction within small-group discussions in a Chinese university setting?

2. What are the verbal behaviours of the participants in this social network?

Since the research was conducted in a Chinese higher education setting, the results can also represent a special phenomenon through the cultural lens.

\section{Methods}

\section{Research setting and participants}

This empirical research was conducted in an 18-week post-graduate seminar entitled "Instructional System Design" at a teacher education university in Northern China. Participants included a full-time university professor and a total of 14 graduate students who volunteered to participate in the study. All participants received the Plain Language Statement of the study and signed the consent form that their performance would be videotaped and further analysed anonymously. In order to keep their profiles confidential, the professor was identified by the code $\mathrm{T}$, while the fourteen students were identified by the codes S1-S14. The 14 graduate students were then divided into three set groups with five students (S1-S5) in Group 1, S10-S14 in Group 3, and four students (S6-S9) in Group 2. The professor asked one student from each group to volunteer as the group leader, with the main responsibility of making appointments with the professor and organising the group activities.

\section{Procedure}

The professor met all the students for three regular class periods ( $1 \mathrm{~h}$ for each regular class period) every week throughout one semester. Each group was assigned one specified research topic at the beginning of the semester. The topic for Group 1 was "How to Identify Instructional Goals", the topic for Group 2 was "How to Conduct Learner Analysis" and the topic for Group 3 was "How to Conduct Evaluation of 
Instruction". During the semester, each group had four to five separate sessions of small-group discussions (1-3 $\mathrm{h}$ per session) with the professor in addition to the regular class periods. During the small-group discussions, students in each group would discuss their research plan and progress with the professor. After all sessions of small-group discussions, each group had to present their research results to the entire class. Their presentation accounted for $30 \%$ of their final grade.

In total, 14 sessions of small-group discussions (5 sessions of Group 1 and Group 3, 4 sessions of Group 2) throughout the semester were collected, coded and further analysed. The length of a video-recorded session was between 90 and $120 \mathrm{~min}$. In total, a length of approximately $1500 \mathrm{~min}$ of interactional scenarios was collected for analysis.

\section{Measures}

To begin with, we used the SNA model to elaborate the social network features of the teacher-student interaction in small-group discussions. SNA is a commonly used research approach in sociology and organisational studies, which offers "a method for mapping group interaction, visualising 'connectedness' and quantifying some characteristics of these processes within a community" (de Laat et al. 2007, p. 90). Rienties et al. (2013) believed that the dynamic use of SNA provided researchers with many new angles in social interaction processes. Freeman (1979) reviewed a number of published measures for the centrality features of SNA and reduced them to three basic concepts namely: degree centrality, betweenness centrality and closeness centrality. Degree centrality includes out-degree and in-degree centrality, which are regarded as two commonly used calculations in social network analysis (Russo and Koesten 2005). Betweenness centrality measures the participants' potential in the social network to control communication with the other members in the given network (Lewis et al. 2008). Since degree centrality usually has a high correlation with the closeness centrality, the present study mainly explored degree and betweenness centrality. The collected data were analysed by two trained coders using the UCInet 6.0 program (Borgatti et al. 2005) on social network level and the Cohen's Kappa of inter-coder reliability is 0.73 .

We realised that SNA by itself was not enough to achieve a full understanding of the social interaction in collaborative small-group learning (Martinez et al. 2003); therefore, our second step was to analyse the verbal behaviours within the teacherstudent interaction. We employed the Flanders' interaction analysis (FIA), proposed by Flanders (1962) focusing on the analysis of the teacher-student verbal statements within classroom communication. It was accepted as an effective measurement for analysing teacher-student interaction by different scholars (Kožić et al. 2013; Sahlberg and Boce 2010; Schempp et al. 2004). FIA defined ten categories of verbal behaviours including seven categories on teacher talk, two categories on student talk and one category on silence and confusion. As shown in Table 1, the present study made a minor modification to the FIA by adding "Asking questions and expecting answers" in the students' talk. Since Chinese students have traditionally been viewed as "passive recipients of knowledge" (Tam et al. 2009, p. 147-148) and seldom ask questions in class, we added the category to discover the percentage of 
Table 1 A modified coding scheme of verbal behaviours (based on Flanders 1962)

\begin{tabular}{|c|c|c|c|c|}
\hline \multicolumn{3}{|c|}{ Categories of verbal behaviours } & $\begin{array}{l}\text { Detailed description } \\
\begin{array}{l}\text { 1. Clarifying students' positive or negative } \\
\text { feelings }\end{array}\end{array}$ & \multirow{2}{*}{$\begin{array}{l}\begin{array}{l}\text { Category } \\
\text { code }\end{array} \\
1\end{array}$} \\
\hline \multirow[t]{7}{*}{$\begin{array}{l}\text { Teacher } \\
\text { talk }\end{array}$} & \multirow[t]{4}{*}{$\begin{array}{l}\text { Indirect } \\
\text { influence }\end{array}$} & $\begin{array}{l}\text { 1. Using student } \\
\text { feeling } \\
\text { constructively }\end{array}$ & $\begin{array}{l}\text { 1. Clarifying students' positive or negative } \\
\text { feelings } \\
\text { 2. Expecting and reflecting on students' } \\
\text { feelings } \\
\text { 3. Using students' feelings constructively }\end{array}$ & \\
\hline & & 2. Giving praise & $\begin{array}{l}\text { 1. Verbal behaviours for giving } \\
\text { encouragement or praise } \\
\text { 2. Nonverbal behaviours for giving } \\
\text { encouragement or praise, such as nodding, } \\
\text { showing hands }\end{array}$ & 2 \\
\hline & & $\begin{array}{l}\text { 3. Clarifying } \\
\text { student ideas }\end{array}$ & $\begin{array}{l}\text { 1. Clarifying students' ideas } \\
\text { 2. Developing student ideas with proper } \\
\text { comments }\end{array}$ & 3 \\
\hline & & $\begin{array}{l}\text { 4. Asking } \\
\text { questions }\end{array}$ & $\begin{array}{l}\text { 1. Asking questions } \\
\text { 2. Expecting or waiting for students' answers }\end{array}$ & 4 \\
\hline & \multirow[t]{3}{*}{$\begin{array}{l}\text { Direct } \\
\text { influence }\end{array}$} & 5. Lecturing & $\begin{array}{l}\text { 1. Giving lectures } \\
\text { 2. Expressing teachers' beliefs } \\
\text { 3. Explaining } \\
\text { 4. Stating other authorities' opinions }\end{array}$ & 5 \\
\hline & & $\begin{array}{l}\text { 6. Giving } \\
\text { directions }\end{array}$ & Giving orders, directions or commands & 6 \\
\hline & & $\begin{array}{l}\text { 7. Justifying } \\
\text { authority }\end{array}$ & $\begin{array}{l}\text { 1. Giving statements in an attempt to change } \\
\text { students' behaviours } \\
\text { 2. Blaming or criticising students } \\
\text { 3. Explaining teachers' verbal and nonverbal } \\
\text { behaviours }\end{array}$ & 7 \\
\hline \multirow[t]{4}{*}{$\begin{array}{l}\text { Student } \\
\text { talk }\end{array}$} & \multicolumn{2}{|c|}{$\begin{array}{l}\text { 8. Talk made in response to a } \\
\text { teacher-initiated contact }\end{array}$} & $\begin{array}{l}\text { 1. Responding to the teacher } \\
\text { 2. Responding to student peers }\end{array}$ & 8 \\
\hline & \multicolumn{2}{|c|}{ 9. Talk initiated by the student } & $\begin{array}{l}\text { 1. Initiating a conversation } \\
\text { 2. Expressing opinions } \\
\text { 3. Initiating a new topic }\end{array}$ & 9 \\
\hline & \multicolumn{3}{|c|}{ 10. Asking questions and expecting answers } & 10 \\
\hline & \multicolumn{3}{|c|}{ 11. Silence or confusion } & 11 \\
\hline
\end{tabular}

students' asking questions in group discussions. Two trained observers recorded each category of verbal behaviours every $3 \mathrm{~s}$ based on the following scheme and the Cohen's Kappa of inter-coder reliability in verbal behaviour analysis is 0.74 .

\section{Results}

The results of social network features and verbal behaviours within small-group discussions are presented below. 


\section{Social network features of small-group discussions}

As shown in Figs. 1, 2 and 3, the results indicate the professor gained the highest out-degree scores in all three groups. The participant's out-degree centrality refers to his or her ability to connect with others in the network. If the participant has high out-degree centrality, it means he is a more active participant and has more direct contact with other members in the social network. Therefore, we conclude that the professor played the most active role in the social communications with the students and had the most direct contact with the students in small-group discussions. Secondly, there was always one student that had the second highest out-degree score compared with other students, such as S1 in Group 1, S6 in Group 2 and S10 in Group 3. We checked the profiles of the students with the highest out-degree scores and found that they were the group leaders who volunteered to lead a group at the beginning of the group setting.

As indicated in Figs. 4, 5 and 6, the professor also had the highest in-degree score in all three groups. S1 in Group 1, S6 in Group 2 and S10 in Group 3 also demonstrated relatively higher in-degree scores than other students. The participant's in-degree centrality represents the degree to which others seek out that particular participant in a social network. The higher the in-degree score a participant has, the more advantageous position he occupies in the social network. Thus, we conclude that the professor and group leaders usually occupied more structurally advantageous positions than other students.

Then, we analysed the betweenness centrality of the small-group discussions. According to Cho et al. (2007), the betweenness score of a participant in a social network indicates the extent to which that participant serves as a structural conduit. Usually, the higher the betweenness score a participant has, the greater extent of the control in the interaction he possesses. The results show that the professor had the largest power and the group leaders had the second largest power to facilitate or limit the interaction (Figs. 7, 8, 9).

\section{Verbal behaviours in small-group discussions}

In order to better understand the teacher-student interaction, we made an analysis of teacher-student verbal behaviours based on the FIA. Table 2 displays the frequency

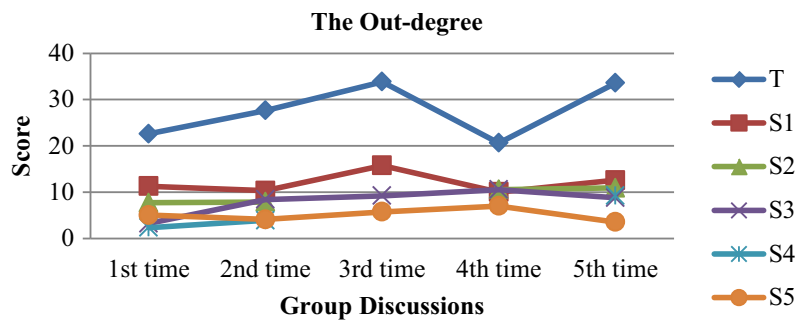

Fig. 1 The out-degree scores of Group 1 


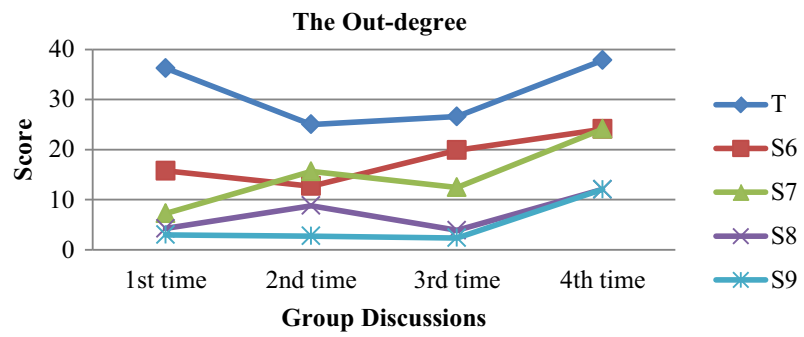

Fig. 2 The out-degree scores of Group 2

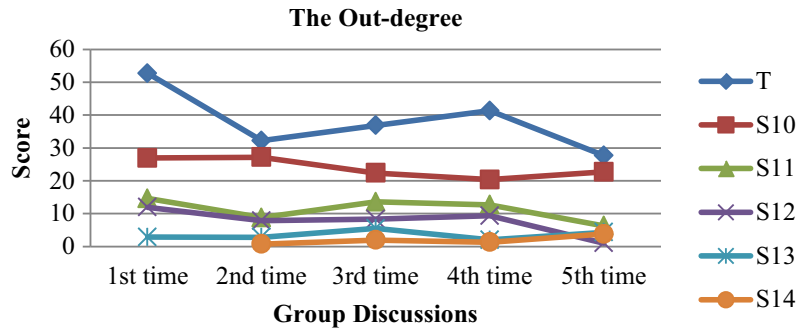

Fig. 3 The out-degree scores of Group 3

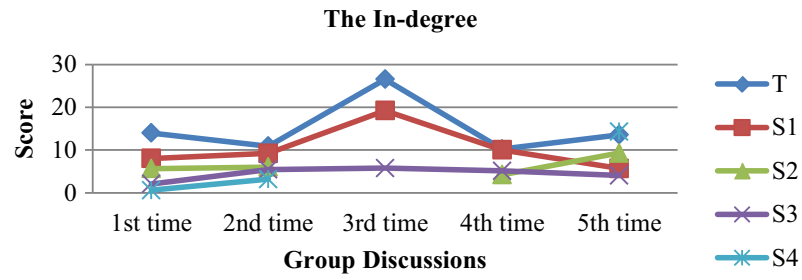

Fig. 4 The in-degree scores of Group 1

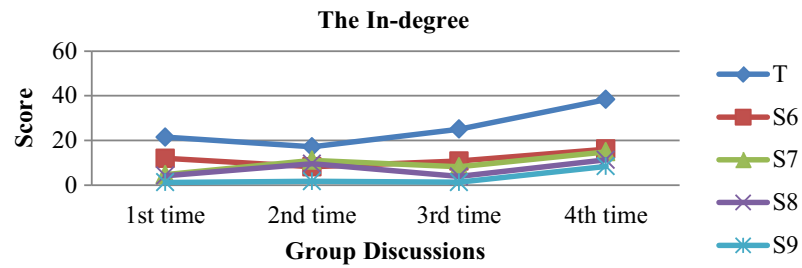

Fig. 5 The in-degree scores of Group 2

of teacher-student verbal behaviours in small-group discussions. It was clear that the professor had the main control of the discussions. Notably, student talk also accounted for a large percentage of the discussions. For example, the percentage of 
The In-degree

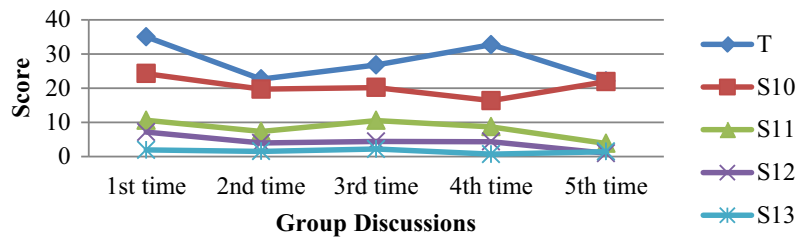

Fig. 6 The in-degree scores of Group 3

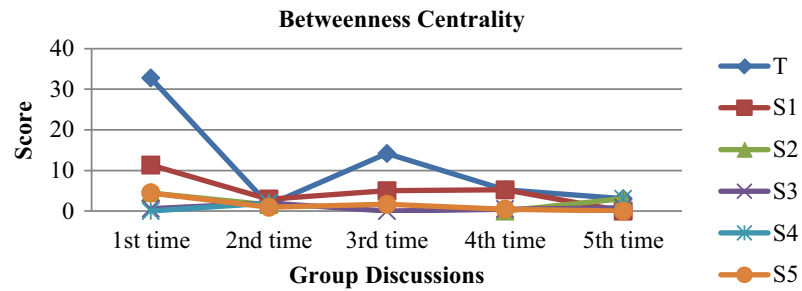

Fig. 7 The betweenness centrality score of Group 1

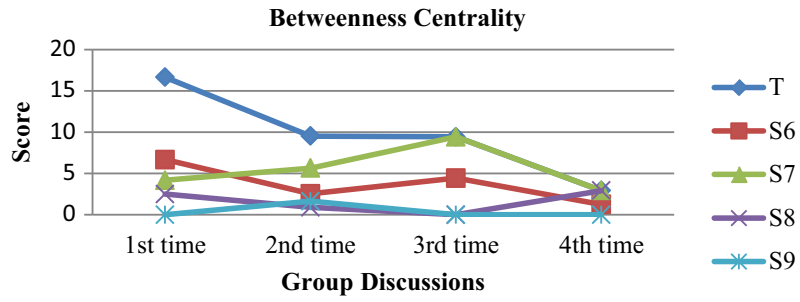

Fig. 8 The betweenness centrality score of Group 2

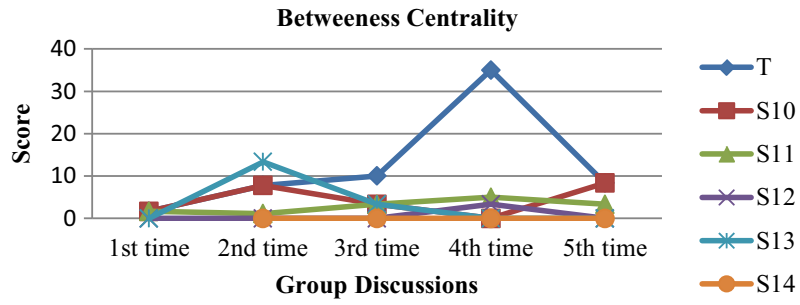

Fig. 9 The betweenness centrality score of Group 3

student talk exceeded the teacher talk in the fourth session of Group 1, and in the second and the fifth session of Group 3.

We then analysed the categories of verbal behaviours in small-group discussions. First, as indicated in Table 3, all three groups had a relatively high percentage of teacher lecturing (Category code $=5$ ), student-initiated talk (Category code $=9$ ) 
Table 2 Frequency of teacher-student verbal behaviours in small-group discussions

\begin{tabular}{lllll}
\hline Group & Discussion & $\begin{array}{l}\text { The percentage of } \\
\text { teacher talk }(\%)\end{array}$ & $\begin{array}{l}\text { The percentage of } \\
\text { student talk }(\%)\end{array}$ & $\begin{array}{l}\text { The percentage of } \\
\text { silence and confusion }(\%)\end{array}$ \\
\hline \multirow{2}{*}{ Group 1 } & The 1st time & 49.66 & 33.16 & 17.18 \\
& The 2nd time & 55.71 & 30.94 & 13.35 \\
& The 3rd time & 66.25 & 21.25 & 12.50 \\
& The 4th time & 28.84 & 58.58 & 12.58 \\
& The 5th time & 44.96 & 39.10 & 15.94 \\
Group 2 & The 1st time & 38.93 & 21.88 & 39.19 \\
& The 2nd time & 34.17 & 23.49 & 42.34 \\
& The 3rd time & 48.41 & 36.35 & 15.24 \\
& The 4th time & 43.70 & 33.31 & 22.99 \\
The 1st time & 50.10 & 19.43 & 30.47 \\
Group 3 & The 2nd time & 39.74 & 47.61 & 12.65 \\
& The 3rd time & 44.86 & 39.05 & 24.16 \\
& The 4th time & 38.43 & 37.41 & 12.38 \\
The 5th time & 34.51 & 53.11 &
\end{tabular}

Table 3 Frequency of the verbal behaviours in small-group discussions

\begin{tabular}{|c|c|c|c|c|c|c|c|c|c|c|c|c|}
\hline \multirow[t]{2}{*}{ Group } & \multirow[t]{2}{*}{ Discussion } & \multicolumn{11}{|c|}{ Category code of verbal behaviours } \\
\hline & & 1 & 2 & 3 & 4 & 5 & 6 & 7 & 8 & 9 & 10 & 11 \\
\hline \multirow[t]{5}{*}{ Group 1} & The 1st time & 0.07 & 2.25 & 13.23 & 0.23 & 32.68 & 0.98 & 0 & 0.60 & 26.60 & 5.48 & 17.66 \\
\hline & The 2nd time & 0 & 0.87 & 8.20 & 1.32 & 44.27 & 1.02 & 0 & 0.41 & 28.83 & 1.58 & 13.40 \\
\hline & The 3rd time & 0 & 3.40 & 29.14 & 0.91 & 28.34 & 4.31 & 0 & 3.06 & 16.21 & 2.04 & 12.70 \\
\hline & The 4th time & 0 & 0.76 & 8.31 & 1.65 & 18.10 & 0 & 0 & 1.21 & 53.78 & 3.56 & 12.63 \\
\hline & The 5 th time & 0 & 0.92 & 14.05 & 1.42 & 28.04 & 0.51 & 0 & 1.02 & 36.08 & 1.98 & 15.98 \\
\hline \multirow[t]{4}{*}{ Group 2} & The 1st time & 0.06 & 0.84 & 3.16 & 0.58 & 32.73 & 1.61 & 0 & 0.64 & 19.72 & 1.55 & 39.11 \\
\hline & The 2nd time & 0 & 0.27 & 3.13 & 2.13 & 28.56 & 0.27 & 0 & 0.60 & 19.37 & 3.60 & 42.48 \\
\hline & The 3rd time & 0.11 & 2.04 & 6.56 & 2.26 & 36.90 & 0.51 & 0 & 1.87 & 31.64 & 2.89 & 15.22 \\
\hline & The 4th time & 0 & 2.78 & 4.75 & 3.95 & 30.94 & 1.43 & 0 & 2.19 & 26.34 & 4.83 & 22.97 \\
\hline \multirow[t]{5}{*}{ Group 3} & The 1st time & 0.13 & 0.13 & 2.26 & 0.93 & 46.00 & 0.67 & 0 & 0.35 & 11.83 & 7.24 & 30.46 \\
\hline & The 2nd time & 0.07 & 3.63 & 3.76 & 1.55 & 29.91 & 0.81 & 0 & 0.47 & 41.53 & 5.58 & 12.70 \\
\hline & The 3rd time & 0.05 & 0.72 & 3.68 & 0.73 & 39.61 & 0.05 & 0 & 3.05 & 30.65 & 5.33 & 16.13 \\
\hline & The 4th time & 0.43 & 4.51 & 3.34 & 1.02 & 26.16 & 2.91 & 0 & 0.87 & 34.74 & 1.74 & 24.27 \\
\hline & The 5th time & 0 & 1.91 & 4.72 & 1.53 & 25.31 & 1.02 & 0 & 1.06 & 50.74 & 1.28 & 12.42 \\
\hline
\end{tabular}

Category code of verbal behaviours: 1 using student feeling constructively, 2 giving praise, 3 clarifying student ideas, 4 asking questions, 5 lecturing, 6 giving directions, 7 justifying authority, 8 talk responding to teacher talk, 9 student-initiated talk, 10 asking questions \& expecting answers, 11 silence or confusion

and clarifying student ideas (Category code $=3$ ). On one hand, teacher lecturing dominated the group discussion for all the three groups. On the other hand, in some sessions of group discussion, the percentage of student-initiated talk exceeded the 
teacher lecturing, such as in the fourth and fifth sessions of Group 1 as well as the second, fourth and fifth sessions of Group 3. The relatively high percentage of student-initiated talk indicated that students had an active participation in smallgroup discussions and enjoyed ample opportunities to air their opinions. Moreover, the professor spent a handsome amount of time clarifying student ideas, which is another indication of the professor's initiative to promote group discussions. Second, the professor did not show any verbal behaviours of justifying his authority (Category code $=7$ ), which indicated that he never attempted to change students' behaviours or criticise students during small-group discussions. These findings may imply that there was a relatively fair atmosphere for thorough negotiation of meaning between the professor and the students.

Finally, we compared the percentage of the professor's and students' verbal behaviours in terms of asking questions. From Table 4, it was clear that students demonstrated the greater percentage of asking questions in class, and thus, we concluded that students also had sufficient opportunities to raise questions and ask the professor for help during small-group discussions.

\section{Discussion}

The main goal of the study was to investigate the nature of teacher-student interaction in small-group discussions. The exploratory case study resulted in the following important findings.

\section{Social network features of small-group discussions}

We discovered two distinctive social network features. First of all, the professor had the highest score of in-degree centrality, out-degree centrality and betweenness in all three small groups. It suggested that the professor occupied the central position in the social network, being the source of communications for the students. It verifies the teacher's traditional role as explainers in the Chinese classroom setting (Huang and Brown 2009). Chinese culture is regarded as being part of the Confucian-heritage and reflecting particularities of a collectivist society (Biggs 1996). The Confucian cultural tradition, combined with other factors such as population pressure, economic and political systems, helps to shape a teacherdominated, and highly structured Chinese pedagogical culture (Zhang 2004). According to Li (2001), Chinese teachers usually enjoy great authority and are highly respected by their students. They are regarded both as authorities and students' moral mentors (Huang 2009).

Another social network feature is that the leaders of all three small groups had the second most important role following the professor. They usually acted the role of a teaching assistant, having a large number of opportunities to talk and having strong influence on other group members' interactional language. It is consistent with the results of Hara et al. (2000), who noted that some participants were more socially engaged, for instance, the discussion moderator or starter held the key role in deciding "the depth of dialogue and overall 
Table 4 Frequency of asking questions in small-group discussions

\begin{tabular}{lllr}
\hline Group & Discussion & $\begin{array}{l}\text { The percentage of the } \\
\text { teacher's verbal behaviours } \\
\text { of asking questions }\end{array}$ & $\begin{array}{l}\text { The percentage of students' } \\
\text { verbal behaviours of asking } \\
\text { questions }\end{array}$ \\
\hline Group 1 & The 1st time & 0.69 & 17.18 \\
& The 2nd time & 2.91 & 5.19 \\
& The 3rd time & 3.10 & 11.25 \\
& The 4th time & 8.36 & 6.20 \\
Group 2 & The 5th time & 6.91 & 5.21 \\
& The 1st time & 1.74 & 7.27 \\
& The 2nd time & 6.96 & 15.65 \\
& The 3rd time & 5.78 & 8.37 \\
Group 3 & The 4th time & 11.32 & 15.83 \\
& The 1st time & 1.90 & 37.96 \\
& The 2nd time & 4.91 & 11.84 \\
& The 3rd time & 1.80 & 14.80 \\
& The 4th time & 3.74 & 4.78 \\
& The 5th time & 5.71 & 2.45 \\
\hline
\end{tabular}

knowledge generation processes" (p. 146). It also echoes with the statement made by Hogg et al. (1998), who claimed that an individual who remains in a leadership position will be more socially active and his or her fundamental attribution effect will be more entrenched. In this case, since the group leaders were volunteers at the beginning of the group setting and did not rotate their role with other group members, it is quite natural that the leaders would hold a more influential role in the social network as the group work continued. However, it also indicated that other group members may act as free riders in the group work. Teng and Luo (2015) claimed that social loafing should be avoided in effective group learning. In order to guarantee the effectiveness of the smallgroup learning, Smith et al. (2005) suggested the leadership role should be shared among group members to ensure structured or cooperative group work. Moreover, teachers should hold an "instructional role" to curb the free riding phenomena (Njie et al. 2013).

\section{Verbal behaviours of small-group discussions}

The analysis of verbal behaviours showed three main categories of verbal behaviours within small-group discussions: teacher lecturing (Category code $=5$ ), student-initiated talk (Category code $=9$ ) and teacher's clarifying student ideas (Category code $=3$ ). Although the professor's discourse was characterised by a large percentage of lecturing, he was also very generous in clarifying student ideas. It indicated that the professor in this case was not only tense in lecturing but also very active in developing student ideas with appropriate comments. This finding echoes the re-interpretation of teachers' role in teacher-student interaction by Kennedy (2002), who stressed that teacher-student relationships in Chinese 
classrooms are neither cold nor authoritarian as they appear at first. Kennedy (2002) claimed the "pastoral role" of Chinese teachers in guiding and mentoring students (p. 439). In our case, we also recognised the similar responsibility the university professor assumed. Therefore, the professor in present research actually acted more like a guide and facilitator, promoting students' group discussions.

Another fact is that the frequency of student talk is also very high in all sessions of small-group discussions. Students were actively involved in discussions through starting a conversation, expressing their opinions and leading discussions on new topics. As shown in Table 4, students also demonstrated a great percentage of asking questions in discussions. The findings are contradictory to earlier findings which claimed that Chinese students were just good listeners and note takers, who seldom tried to impose their opinions on others (Charlesworth 2008; Huang and Brown 2009) or rarely asked questions in class.

\section{Conclusion}

The rapid development of information technology has provided enormous potential for promoting learning and teaching, but clearly, the application of technology to improve education is "not a simple matter" (Roschelle et al. 2000, p. 92). Zhao et al. (2002) suggested teachers should take "an evolutionary rather than a revolutionary view" (p. 512) on changes caused by technological innovations and reflect very carefully before implementing innovative technologies in their own classrooms. The present study was an attempt to further explore the nature of smallgroup discussions in actual classroom interaction in a Chinese university setting. We believed a thorough understanding of teacher-student interaction in actual classroom teaching is a crucial condition for the successful application of innovative technologies.

In this study, we investigated social network and verbal behavioural features of teacher-student interaction in small-group discussions in a Chinese higher education setting. The findings revealed a complicated picture. First of all, the professor possessed the central role in the social network and spent a large percentage of discussion time in lecturing, which is in line with several earlier studies. In traditional Chinese culture, teachers usually acted as the main controller of the classroom. However, the professor also spent much time clarifying and further developing learners' ideas and shared a high percentage of classroom talk with the students. The findings are consistent with Webb's findings that the effective teacher usually played a multi-dimensional role in collaborative small-group learning (Webb 2009). It revealed a new perspective of Chinese teacher's role in small-group learning with graduate students.

Secondly, the verbal behaviours of students in this research showed quite different features compared with previous literature (Charlesworth 2008; Huang and Brown 2009). Students had been verbally active in group discussions. Instead of sitting quietly as listeners, they were very confident in initiating their statements and raising questions, contrary to popular stereotypes of Chinese students as rigid rote learners (Gan 2009; Lord et al. 2013; Watkins 2000). The findings also echo the 
earlier studies about the misconceptions of Chinese learners as being reticent participants and demonstrating lower activity levels in classrooms (Cheng et al. 2011; Cheng 2000; Wang et al. 2009). We can conclude the relationship between the professor and students in this case study was relatively democratic, and the findings can be a possible reflection of the changing classroom atmosphere in Chinese university settings.

This small-scale investigation offers support to explain the social network and verbal behavioural features of teacher-student interaction in small-group discussions in a Chinese higher education setting. It adds new information to the substantial previous literature about small-group work and gives implications for further understanding the teacher-student interaction in Chinese culture. Working in a group is known to be very complex (Decuyper et al. 2010), and the classroom environment provides a dynamic setting (Stronge 2007) for group work. Recently, in Mainland China, higher education policy makers and practitioners have increasingly employed "group work" as a teaching strategy in higher education settings ( $\mathrm{Li}$ et al. 2014). The rationale behind the initiative is to encourage "exploratory, discussion-based and participatory" teaching and learning in higher education (AEI 2010). In order to promote the effective group work in higher education, we suggest Chinese professors give more opportunities for graduate students to talk, establish positive interdependence among group members and encourage them to interact with one another to achieve success.

Acknowledgments We would like to show our gratitude to all the reviewers and editors who have provided insightful comments and suggestions. We also want to thank Professor Tsai Chin-Chung for his invaluable comments on the revision of the article. The research is funded by the Humanities and Social Sciences Fund of Chinese Ministry of Education (Grant 13YJA880040, awarded to Mang Li) and the Beijing Higher Education Young Elite Teacher Project (Grant YETP0463, awarded to Chunping Zheng).

\section{References}

AEI (2010). Outline of China's national plan for medium and long-term education reform and development. Retrieved May 15, 2013 from Commonwealth of Australia website: http://www.aei. gov.au/news/newsarchive/2010/documents/china_education_reform_pdf.pdf.

Alavi, M. (1994). Computer-mediated collaborative learning-an empirical-evaluation. MIS Quarterly, $18(2), 159-174$.

Anderson, R. C., Nguyen-Jahiel, K., McNurlen, B., Archodidou, A., Kim, S. Y., Reznitskaya, A., \& Gilbert, L. (2001). The snowball phenomenon: Spread of ways of talking and ways of thinking across groups of children. Cognition and Instruction, 19(1), 1-46.

Auster, C. J., \& Macrone, M. (1994). The classroom as a negotiated social setting-an empirical-study of the effects of faculty members behavior on students participation. Teaching Sociology, 22(4), 289-300.

Barnes, D., \& Todd, F. (1977). Communication and learning in small groups. London: Routledge \& Kegan Pau.

Biggs, J. B. (1996). Western misperceptions of the Confucian-heritage learning culture. In D. A. Watkins \& J. B. Biggs (Eds.), The Chinese learner: Cultural, psychological and contextual influences (pp. 45-67). Hong Kong: Comparative Education Research Centre, Hong Kong University.

Borgatti, S., Everett, M., \& Freeman, L. C. (2005). UCINET 6 for windows software for social network analysis. Harvard, MA: Analytic Technologies.

Carroll, D. (2005). Learning through interactive talk: A school-based mentor teacher study group as a context for professional learning. Teaching and Teacher Education, 21(5), 457-473. 
Charlesworth, Z. M. (2008). Learning styles across cultures: Suggestions for educators. Education and Training, 50(2), 115-127.

Chen, J. (2014). Teachers' conceptions of approaches to teaching: A Chinese perspective. The AsiaPacific Education Researcher, 24(2), 341-351.

Cheng, X. (2000). Asian students' reticence revisited. System, 28(3), 435-446.

Cheng, H., Andrade, H. L., \& Yan, Z. (2011). A cross-cultural study of learning behaviours in the classroom: From a thinking style perspective. An International Journal of Experimental Educational Psychology, 31(7), 825-841.

Chi, M. T. H. (2009). Active-constructive-interactive: A conceptual framework for differentiating learning activities. Topics in Cognitive Science, 1(1), 73-105.

Chi, M. T. H., Roy, M., \& Hausmann, R. G. M. (2008). Observing tutorial dialogues collaboratively: Insights about human tutoring effectiveness from vicarious learning. Cognitive Science, 32(2), 301-341.

Cho, H., Gay, G., Davidson, B., \& Ingraffea, A. (2007). Social networks, communication styles, and learning performance in a CSCL community. Computers \& Education, 49(2), 309-329.

Christoph, J. N., \& Nystrand, M. (2001). Taking risks, negotiating relationships: One teacher's transition toward a dialogic classroom. Research in the Teaching of English, 36(2), 249-286.

Cohen, E. G. (1994). Restructuring the classroom-conditions for productive small-groups. Review of Educational Research, 64(1), 1-35.

Coll, C., Rochera, M. J., \& de Gispert, I. (2014). Supporting online collaborative learning in small groups: Teacher feedback on learning content, academic task and social participation. Computers \& Education, 75, 53-64.

Cotten, S. R., \& Wilson, B. (2006). Student-faculty interactions: Dynamics and determinants. Higher Education, 51(4), 487-519.

de Laat, M., Lally, V., Lipponen, L., \& Simons, R. J. (2007). Investigating patterns of interaction in networked learning and computer-supported collaborative learning: A role for social network analysis. International Journal of Computer-Supported Collaborative Learning, 2(1), 87-103.

Decuyper, S., Dochy, F., \& Van den Bossche, P. (2010). Grasping the dynamic complexity of team learning: An integrative model for effective team learning in organisations. Educational Research Review, 5(2), 111-133.

Flanders, N. A. (1962). Using interaction analysis in the inservice training of teachers. Journal of Experimental Education, 30(4), 313-316.

Freeman, L. C. (1979). Centrality in social networks conceptual clarification. Social Networks, 1(3), 215-239.

Gan, Z. D. (2009). 'Asian learners' re-examined: An empirical study of language learning attitudes, strategies and motivation among mainland Chinese and Hong Kong students. Journal of Multilingual and Multicultural Development, 30(1), 41-58.

$\mathrm{Gu}$, P. (2009). Emphysizing research-based teaching and promoting the reform of classroom pedagogies (Bawoyanjiuxingjiaoxue Cujinketangjiaoxuefangfagaige). China Higher Education, 7, 31-38.

Hara, N., Bonk, C. J., \& Angeli, C. (2000). Content analysis of online discussion in an applied educational psychology course. Instructional Science, 28(2), 115-152.

Hatano, G. (1993). Time to merge Vygotskian and constructivist conceptions of knowledge acquisition. In E. A. Forman, N. Minick, \& C. A. Stone (Eds.), Contexts for learning: Sociocultural dynamics in children's development (pp. 153-166). New York: Oxford University Press.

Hogg, M. A., Hains, S. C., \& Mason, I. (1998). Identification and leadership in small groups: Salience, frame of reference, and leader stereotypicality effects on leader evaluations. Journal of Personality and Social Psychology, 75(5), 1248-1263.

Huang, J. (2009). What happens when two cultures meet in the classroom? Journal of Instructional Psychology, 36(4), 335-342.

Huang, J., \& Brown, K. (2009). Cultural factors affecting Chinese ESL students' academic learning. Education, 129(4), 643-653.

Kennedy, P. (2002). Learning cultures and learning styles: Myth-understandings about adult (Hong Kong) Chinese learners. International Journal of Lifelong Education, 21(5), 430-445.

King, R. B., \& Ganotice, F. A, Jr. (2014). The social underpinnings of motivation and achievement: Investigating the role of parents, teachers, and peers on academic outcomes. The Asia-Pacific Education Researcher, 23(3), 745-756.

Kožić, D., Globočnik Žunac, A., \& Bakić-Tomić, L. (2013). Use of non-verbal communication channels in the classroom. Croatian Journal of Education, 15(Sp. Ed. 1), 141-153. 
Kreijns, K., Kirschner, P. A., \& Jochems, W. (2003). Identifying the pitfalls for social interaction in computer-supported collaborative learning environments: A review of the research. Computers in Human Behavior, 19(3), 335-353.

Kwon, K., Liu, Y. H., \& Johnson, L. P. (2014). Group regulation and social-emotional interactions observed in computer supported collaborative learning: Comparison between good vs. poor collaborators. Computers \& Education, 78, 185-200.

Lewis, K., Kaufman, J., Gonzalez, M., Wimmer, A., \& Christakis, N. (2008). Tastes, ties, and time: A new social network dataset using Facebook.com. Social Networks, 30(4), 330-342.

Li, J. (2001). Chinese conceptualization of learning. Ethos, 29(2), 111-137.

Li, J., \& Lin, J. (2008). China's move to mass higher education: An analysis of policy making from a rational framework. In D. P. Baker \& A. W. Wiseman (Eds.), The worldwide transformation of higher education: International perspectives on education and society (pp. 269-295). Bingley, UK: JAI Press.

Li, D. M., Remedios, L., \& Clarke, D. (2014). Chinese students' groupwork practices and experiences in China. Higher Education, 68(2), 227-241.

Lord, S. M., McGaughey, K. J., Chen, J. C., Chang, V. W., \& IEEE. (2013). Measuring propensity for lifelong learning: Comparing Chinese and US engineering students. In 2013 IEEE Global Engineering Education Conference (pp. 329-334). New York: IEEE.

Lou, Y. P., Abrami, P. C., Spence, J. C., Poulsen, C., Chambers, B., \& d'Apollonia, S. (1996). Withinclass grouping: A meta-analysis. Review of Educational Research, 66(4), 423-458.

Martinez, A., Dimitriadis, Y., Rubia, B., Gomez, E., \& de la Fuente, P. (2003). Combining qualitative evaluation and social network analysis for the study of classroom social interactions. Computers \& Education, 41(4), 353-368.

McDonough, Kim. (2004). Learner-learner interaction during pair and small group activities in a Thai EFL context. System, 32(2), 207-224.

McKeachie, Wilbert James, \& Hofer, Barbara K. (2002). McKeachie's teaching tips: Strategies, research, and theory for college and university teachers (11th ed.). Boston: Houghton Mifflin Co.

Murphy, P. K., Wilkinson, I. A. G., Soter, A. O., Hennessey, M. N., \& Alexander, J. F. (2009). Examining the effects of classroom discussion on students' comprehension of text: A meta-analysis. Journal of Educational Psychology, 101(3), 740-764.

Njie, Baboucarr, Asimiran, Soaib, \& Basri, Ramli. (2013). An exploratory study of the free riding debacle in a Malaysian University: Students' perspectives. The Asia-Pacific Education Researcher, 22(3), 257-262.

Nystrand, M. (2006). Research on the role of classroom discourse as it affects reading comprehension. Research in the Teaching of English, 40(4), 392-412.

Osborne, J. (2010). Arguing to learn in science: The role of collaborative, critical discourse. Science, 328(5977), 463-466.

Renn, K. A., Brazelton, G. B., \& Holmes, J. M. (2014). At the margins of internationalization: An analysis of journal articles on college student development, learning, and experiences, 1998-2011. Journal of College Student Development, 55(3), 278-294.

Rienties, B., Héliot, Y., \& Jindal-Snape, D. (2013). Understanding social learning relations of international students in a large classroom using social network analysis. Higher Education, 66(4), 489-504.

Roschelle, J. M., Pea, R. D., Hoadley, C. M., Gordin, D. N., \& Means, B. M. (2000). Changing how and what children learn in school with computer-based technologies. Future of Children, 10(2), 76-101.

Russo, Tracy C., \& Koesten, Joy. (2005). Prestige, centrality, and learning: A social network analysis of an online class. Communication Education, 54(3), 254-261.

Sahlberg, P., \& Boce, E. (2010). Are teachers teaching for a knowledge society? Teachers and Teaching: Theory and Practice, 16(1), 31-48.

Schempp, P., McCullick, B., St Pierre, P., Woorons, S., You, J., \& Clark, B. (2004). Expert golf instructors' student-teacher interaction patterns. Research Quarterly for Exercise and Sport, 75(1), 60-70.

Smith, K. A., Sheppard, S. D., Johnson, D. W., \& Johnson, R. T. (2005). Pedagogies of engagement: Classroom-based practices. Journal of Engineering Education, 94(1), 87-101.

Stronge, J. (2007). Qualities of effective teachers. Alexandria, VA: Association for Supervision and Curriculum Development.

Sun, Q. (2006). The transformation of teaching strategy: From monologue to dialogue (Jiaoxuecelvdezhuanxing: congdubaidaoduihua). Global Education, 35(6), 42-45. 
Tam, K. Y., Heng, M. A., \& Jiang, G. (2009). What undergraduate students in China say about their professors' teaching. Teaching in Higher Education, 14(2), 147-159.

Teng, C. C., \& Luo, Y. P. (2015). Effects of perceived social loafing, social interdependence, and group affective tone on students' group learning performance. The Asia-Pacific Education Researcher, 24(1), 259-269.

Wang, M. J., Shen, R. M., Novak, D., \& Pan, X. Y. (2009). The impact of mobile learning on students' learning behaviours and performance: Report from a large blended classroom. British Journal of Educational Technology, 40(4), 673-695.

Watkins, David. (2000). Learning and teaching: A cross-cultural perspective. School Leadership \& Management, 20(2), 161-173.

Webb, N. M. (2009). The teacher's role in promoting collaborative dialogue in the classroom. British Journal of Educational Psychology, 79(1), 1-28.

Weinberger, A., \& Fischer, F. (2006). A framework to analyze argumentative knowledge construction in computer-supported collaborative learning. Computers \& Education, 46(1), 71-95.

Zhang, J. W. (2004). Using ICT to prepare learners for the 21st century: The perspectives of eastern APEC economies. Paper presented at the APEC Summit on Educational Innovation: "Striking Blance: Sharing Practice from East and West", Beijing.

Zhao, Y., Pugh, K., Sheldon, S., \& Byers, J. (2002). Conditions for classroom technology innovations. The Teachers College Record, 104(3), 482-515.

Zheng, J. (2001). Restructuring the classroom. Journal of East China Normal University, 19(3), 53-63.

Mang Li is a Professor at Beijing Normal University (BNU), China, where he also serves as the Director of the Center for Faculty Development. He is also the Director of Teaching and Learning Research Center in the Faculty of Education at BNU. He has a Ph.D. degree in Education, and his research interests focus on the fundamental theories of educational technology, instructional design, and faculty development. He has authored or edited over 20 books, and his recent book Exploring Learning \& Teaching in Higher Education has about 16 research articles discussing effective strategies for promoting learning in higher education. He has also published more than 100 research papers on the theories of educational technology and instructional design.

Chunping Zheng is presently a Ph.D. candidate in the Faculty of Education at Beijing Normal University. She is also an in-service lecturer at the Department of Foreign Languages at Beijing University of Posts and Telecommunications (BUPT). Her research interests focus on computer-assisted language learning. She has published over ten research papers and edited or translated three books. Prior to commencing her doctoral studies, she has been an English teacher at BUPT for eight years, where she worked with her research team and developed an online formative assessment system for English learners in China. In year 2013, she was awarded as the "Beijing Higher Education Young Elite Teacher".

Xiaolan Tang is a PhD student working at the University of Hong Kong. Prior to beginning the PhD program, She got a Master of Science degree from Beijing Normal University, China. She took part in a variety of projects, involving qualitative and quantitative analysis of collaborative learning process with teacher participation, as well as analysis of the effective application of different technologies, such as interactive whiteboards and computers in collaboration. From these experiences, she developed research interests in Learning Science, Collaborative Learning, and Knowledge Building. She is currently working on the research of integration of Mind-Mapping technology in collaborative learning in elementary science.

Guoyuan Sang is currently an Associate Professor in the Center for Teacher Education Research, Faculty of Education, Beijing Normal University. He obtained his $\mathrm{PhD}$ in educational science from Ghent University of Belgium. His research interests are teacher education, ICT integration, teaching and learning theory, and educational anthropology. He has published more than 20 research papers on teacher beliefs, teacher cognitions, TPACK, ICT integration, and school-university partnerships. 